\title{
Determinants of nurse faculty intention to remain employed
}

\author{
Ann E. Tourangeau ${ }^{1}$, Heather Thomson ${ }^{1}$, Margaret Saari $^{1}$, Kimberley Widger $^{1}$, Era Mae Ferron ${ }^{1}$, \\ Kathleen MacMillan ${ }^{2}$ \\ ${ }^{1}$ Lawrence S. Bloomberg Faculty of Nursing, University of Toronto, Toronto, Canada \\ ${ }^{2}$ School of Health Sciences, Humber College, Toronto, Canada \\ Email: tourangeau.reasearch@utoronto.ca
}

Received 13 April 2012; revised 16 May 2012; accepted 30 May 2012

\begin{abstract}
Shortage of nurses is a major concern across healthcare systems. One contributing factor that has received little attention is the shortage of adequately prepared nurse faculty. The nurse shortage will be exacerbated if the supply of adequately prepared nurse faculty is insufficient. Little is known about the factors that influence nurse faculty to remain employed. Focus groups were conducted in 2011 with nurse faculty from both colleges and universities in Ontario, Canada. Six focus groups including $\mathbf{3 7}$ participants were held with different groups of nurse faculty in geographically diverse areas of the province. Focus group transcripts were reviewed by five members of the research team using thematic analysis strategies to identify factors related to nurse faculty intention to remain employed. Nurse faculty members' intention to remain employed was influenced by factors that fell into four thematic categories: personal characteristics, work environment and organizational support, job content, and external characteristics. Each thematic category includes several factors reported to influence nurse faculty intention to remain employed. The "Determinants of Nurse Faculty Intention to Remain Employed" Model is hypothesized. Strategies to address modifiable factors and support non-modifiable factors are suggested to promote retention of nurse faculty. Additional research is needed to test the hypothesized model of nurse faculty intention to remain employed.
\end{abstract}

Keywords: Nurse Faculty Retention; Work Environment; Organizational Support; Theory Development; Focus Groups; Nursing Workforce

\section{INTRODUCTION}

According to the Canadian Nurses Association [CNA], there will be a shortfall of approximately 60,000 fulltime equivalent Registered Nurses (RNs) across Canada by 2022 [1]. To alleviate this shortage, various strategies have been implemented to recruit more nurses as well as to retain those already employed. For example, strategies such as increasing the number of seats in nursing education programs and new nurse graduate guarantees of employment are aimed at increasing recruitment, while strategies such as the late career initiative are aimed at retaining nurses in the workforce [2-4]. These strategies, though useful, do not address all contributing factors to the nursing shortage. An additional contributing factor relates to the shortfall of adequately prepared nurse faculty. Shortages of nurse faculty limit capacity to educate new nurses, and to prepare nurses with graduate education. Fifty two percent of Canadian nurse faculty are 50 years of age or older and are quickly approaching the normal retirement age of 65 years [5]. If there are insufficient numbers of faculty to educate nurses, the projected shortage will be exacerbated in the face of other mitigating strategies [5-8]. Very few studies on nursing human resource planning have focused on the problem of nurse faculty supply. As well, few strategies have been developed and implemented to promote nurse faculty retention. This paper reports on findings from a study designed to narrow the gap in knowledge related to determinants of nurse faculty retention.

\section{BACKGROUND}

Although there have been numerous studies exploring nurse retention, few have focused on nurse faculty retention. It has been suggested that insufficient supply of nurse faculty is driven by a general lack of interest in academia and the availability of greater career opportunities with lucrative salaries outside of academia [6,7, $9,10]$. Additionally, there is evidence that those currently employed in academia are often dissatisfied with workloads. For example, in the National League for Nursing/ 
Carnegie Foundation 2007 survey 45\% of nurse educators reported that they were dissatisfied with their workload [11]. A lack of full-time permanent positions may also be making nurse faculty recruitment and retention more challenging [5]. In a recent Canadian survey, 56.3\% of faculty reported working in part-time contract positions [5]. If one strategy to sustain an adequate supply of nurse faculty is to promote nurse faculty retention, it is imperative that we understand determinants of nurse faculty retention. It is through development, implementation, and evaluation of strategies that manage modifiable determinants of nurse faculty intention to remain employed (and ultimately retention) that nurse faculty can be enticed to remain employed up to and, as needed, beyond the normal age of retirement.

Garbee and Killacky [12] studied a sample of 316 US nurse faculty and reported the following determinants of intention to remain employed (ITR): organizational commitment, workload, job satisfaction and leadership. Although mentorship was hypothesized to be important to new faculty, there was no significant relationship found between mentorship and nurse faculty ITR. Factors that may negatively or positively influence ITR through job satisfaction include the following: being part of student success; student attitudes; flexibility, colleagues/collegial environment; leadership; autonomy and academic freedom; love of nursing; altruism; mentorship; working in an environment with an image of excellence; time demands; low pay; faculty attitudes and lack of accountability; work environment; bureaucracy; not having mentors or socialization; long commute times to work, and faculty shortage.

More recently, Foxall, Megel, Grigsby and Billings [13] surveyed 56 faculty members from a Midwestern university college of nursing. When asked what would make them stay in their current role for an additional three to four years or beyond their anticipated retirement, respondents indicated that decreased workload, increased available resources, professional and personal characteristics, adequate personal health, and supportive work environment characteristics would entice them to stay.

Williamson et al. [8] conducted a qualitative study with six nurse faculty aged 62 years or older to examine factors that influence their ITR. Results included five themes: security (income and benefits); health promotion (belief that health will deteriorate with retirement); relationships (with colleagues and students, mentorship); ego protection (being able to stay current, feelings of worth) and; fulfillment (love of the job).

Gazza [14] used hermeneutic phenomenology to understand the lived experience of full-time nursing faculty to determine recruitment and retention strategies. Based on findings from eight participants, five themes were identified: making a difference for students, the profess- sion and the world; being a gatekeeper for the profession; balancing multiple roles; receiving and providing support; and building relationships [14].

Taken together, this body of research indicates the following are determinants of nurse faculty ITR: effective faculty leadership [12]; experiencing personal health [8, $13]$; support within the work environment $[8,13,14]$; relationships with colleagues and students [8,14]; fulfillment and other personal rewards [8]; and having a manageable workload $[12,13]$.

\section{THE STUDY}

\subsection{Purpose}

The purpose of this study was to explore nurse faculty reported determinants of ITR in a Canadian setting. The ultimate goal was to develop a theoretical model of determinants of nurse faculty ITR that will be tested and revised.

\subsection{Design}

This descriptive exploratory study was carried out using focus group methodology.

\subsection{Participants}

In the Province of Ontario, Canada, a baccalaureate degree in nursing is required for entry to practice as a Registered Nurse [15]. There are 35 universities and colleges in Ontario that offer a baccalaureate degree nursing program either independently or as part of a collaborative model [16]. A sample of nurses in faculty positions at colleges and universities in geographically dispersed regions of the province were invited to participate in a series of focus groups to explore factors influencing their ITR. Six focus groups were completed to achieve data saturation. Participants were recruited through purposive sampling methods with the following inclusion criteria:

- Able to participate in a 60 - 90 minutes focus group interview in a designated room on campus

- Able to read and speak English

- Able to provide informed and written consent

- Were involved in teaching undergraduate or graduate nursing students over the past year.

Tenure and non-tenure stream university faculty as well as full and part-time college faculty were invited to participate. Invitations to participate were initially presented to the Dean or Director of the faculty or school of nursing, who then facilitated the invitation of nurse faculty to participate in the study. Invitations to potential participants were sent via email and by posting paper flyers in faculty lounges and common areas. Included in the invitation was an introduction to the study, participant inclusion criteria, focus group date and time, as well 
as contact information for receiving additional information or for registering for focus group participation. Over the six focus groups, there were a total of 37 participants (average of 6.2 participants per group; range $3-9$ ). Although no compensation was offered for participation, a light lunch was provided. Focus groups were planned around convenient times for participants within each college or university.

\subsection{Data Collection}

Focus groups were led by two moderators: one researcher and one research assistant. Discussion was facilitated by the researcher, while the research assistant attended to participants' needs, assisted with obtaining informed consent to participate, and recorded field notes. Sessions were recorded using digital recorders and transcribed verbatim in preparation for analysis. Use of field notes, recordings and transcripts provided the opportunity for verifiable analysis and confirmability $[17,18]$.

An interview guide was developed around one central question posed at the beginning of each focus group: "What factors in your work or life influence your decision to stay or leave your faculty position?” Data collection and analysis were concurrent. Probing questions were used, when needed, to further explore issues or concepts raised in previous focus groups.

\subsection{Ethical Considerations}

Ethical approval was received from the university ethics review board as well as from the ethics review boards at participating educational institutions.

\section{DATA ANALYSIS}

Thematic analysis strategies were used to reduce data for categorization, summary, and reconstruction to highlight key concepts [19]. Analysis began by having five researchers independently read and re-read transcripts to gain an initial understanding of the content. Researchers identified recurring themes and meanings that were evident in the data. An initial set of codes was assigned to the text by each researcher [17]. Individual codes were compared to authenticate and validate findings and to agree on final codes and meanings. Codes were then grouped into categories for further analysis and to facilitate understanding. Patterns were identified by compareing and contrasting within groups and between groups $[17,19]$. As analysis continued, particular attention was paid to the language faculty used to describe factors influencing their ITR. Further interpretive reading of transcripts helped to refine thematic categories that emerged [17]. Once consensus was reached among researchers, a hypothesized theoretical model explaining nurse faculty
ITR was constructed.

Verification strategies were implemented throughout the study to ensure reliability and validity [20]. These verification strategies included ensuring methodological coherence, appropriate sampling, concurrent data collection and analysis, thinking theoretically, and theory development [20]. Methodological coherence was established by continually validating that the research methods (e.g., focus groups) were appropriate to answer research questions. Appropriate sampling was achieved by obtaining participants from both colleges and universities throughout the Province of Ontario. This sampling approach allowed researchers to achieve data saturation and replication of results [20]. Concurrent data collection and analyses were achieved by initiating analysis while data collection was underway. Thinking theoretically was achieved by confirming initial ideas with new data. Finally, theory development was established through the creation of a hypothesized theoretical model that will be tested and refined.

\section{RESULTS}

Focus group analyses yielded the following four overarching thematic categories of factors influencing nurse faculty ITR: personal characteristics, work environment and organizational support, job content, and external environment characteristics. Thematic categories and related concepts are described below.

\subsection{Personal Characteristics}

In all focus groups, nurse faculty discussed the impact of their personal situations on their ITR. Factors such as age and proximity to retirement, marital status and job opportunities for partners, having dependents, and health status were identified as having varying levels of influence on faculty ITR. The ability to look for employment elsewhere or to simply leave employment (e.g., retire) were also identified influencing factors on ITR. Proximity in years from the normal age of retirement was consistently identified as having an influence on whether or not faculty would consider remaining employed or look for alternate employment. One participant said:

I'm so close to retirement that at this point I would see my retirement out before I would move.

Many participants described how family circumstances affect their ITR and ultimately, retention. In some cases, partners' jobs dictated a move even when they were satisfied with their faculty position. Additionally, lack of job opportunities in the community for partners was reported as limiting where one could reasonably seek an alternate faculty position. One nurse faculty described the impact her partner's job status had on her faculty employment. 


\section{I might consider leaving here if my husband lost his job.}

Many nurse faculty identified the importance of having balance between work and home life. Some participants identified working many more hours than they would in a typical full-time job. Some expressed appreciation for flexibility in work hours because this allowed them to attend to family responsibilities when needed. However, this also meant working late into the night or on weekends to meet deadlines. One faculty stated:

Workload is a big, big, big issue. I think it is very difficult when you have children. I think that turns a lot of people off. Although there is flexibility to the time, the workload is just so enormous that I think it affects family life.

\subsection{Work Environment and Organizational Support}

Work environment and organizational characteristics were discussed in all focus groups as critical factors influenceing initial faculty recruitment as well as ongoing ITR. The quality of faculty/school leadership and the organizational climate of the institution were identified as key influencing factors. Quality leadership was described by nurse faculty as a Dean or Director who provides support through a variety of tactics such as being respectful, approachable, accommodating, and providing consistent direction and feedback. One faculty member described an example of the impact of the leadership capacity of her Dean:

The Dean called me in and said "I hear you're having some problems; what can we do to make it better?" She worked with me to alter my teaching assignment. That really impressed me that she cared enough about me and how I was coping.

Another aspect of leadership identified as influencing faculty ITR was Dean/Director fairness, particularly when assigning teaching and other workload. Participants reported being more inclined to consider leaving their jobs when leadership was lacking or when they did not feel appreciated in the organization. For example, one faculty member recounted an event which diminished feelings of support by the educational organization:

Our pay has been reduced because of deficits. This is just the sort of thing that makes you feel devalued by the institution... and made me start thinking more seriously about leaving my faculty position.

Alternatively, feeling appreciated and valued by the organization was identified as reflecting a positive organizational climate that strengthened ITR. Nurse faculty described a positive organizational climate as having an open atmosphere, clear and transparent decision making procedures, and visible and accessible leaders. Positive and open work environments were identified as leading to the development of strong supportive relationships among colleagues. Supportive relationships were characterized as those built on reciprocity, acceptance of diverse ideas, mutual trust, collaboration, and respect. For example, one faculty member stated:

My relationships with colleagues are what keeps me here. When I think about leaving this institution to go somewhere else, I think about leaving them behind and that is a really hard decision to make.

Conversely, some faculty described their job as isolating and sometimes plagued with competition among colleagues. In some organizations, orientation and mentorship programs were identified as aiding to develop a sense of collegiality.

The quality of the physical work environment was a topic discussed within all groups. Faculty felt that access to resources including adequate physical space, parking, library services, equipment and technology (e.g., phones, computers, internet, and a simulation laboratory) was another key influencing factor promoting ITR. Access to support personnel such as teaching assistants, administrative staff, and technical support were also felt to be important in encouraging them to remain employed.

While nurse faculty in all focus groups discussed the importance of being adequately paid for their work, there was diversity in perceptions of adequacy of remuneration. Some faculty expressed a desire for higher pay while others believed they were well compensated. There was considerable discussion about the loss of income associated with faculty positions compared to positions in healthcare organizations. Participants also discussed the importance of job benefits that influence their ITR including vacation, sabbatical and research leaves, and parental leaves.

Discussions around part-time faculty positions revealed some discomfort with part-time remuneration, benefits, and resources available. Some participants reported being dissatisfied with their part-time status and identified that such status necessitates their seeking alternate employment. The ability to have choice regarding one's employment status (full-time versus part-time) was identified as having an important positive impact on ITR. According to one participant:

It is great to be part-time if you want to be part-time. It is not great to be part-time if you don't want to be part-time, because you will be looking for a full-time job and you're going to leave.

Additionally, promotion opportunities within the organization were identified as motivation to remain employed. Related to this was the perceived support for continuing education and recognition of newly achieved credentials. Some faculty was satisfied by support provided for continuing education while others expressed 
discontent with barriers to participating in continuing education.

\subsection{Job Content}

Participants across focus groups discussed how autonomy was an important component of nurse faculty positions. Autonomy was described as the ability to be innovative and creative, as well as to have choice, flexibility, freedom and independence within the role. For example, one participant said:

I find autonomy in this position is probably one of my biggest draws and one of the biggest joys because I feel I can grow as a person.

Variety in the faculty role was identified as influenceing ITR. Faculty described role variety as a source of both challenge and stimulation. For example, it was noted that variety in the faculty role could be the source of work overload as illustrated by this comment:

I like the variety, but with that variety comes all kinds of responsibilities and accountabilities. You're marking papers; you're teaching courses; you're working on a research project; you've got a paper that you're just getting ready to send out... All that variety adds to a tremendous workload.

Research scholarship expectations for faculty varied considerably between educational settings. Not all participants were interested in engaging in research, while for others, research was described as the most important part of their position. In those educational institutions which had significant research-related expectations of faculty, support and time to conduct research was seen as an important factor in encouraging them to remain employed. For example, one participant stated:

There is strong support here for research. That is what keeps me here.

The value of a broad interpretation of faculty scholarship was discussed, particularly by faculty working in organizations that did not have considerable requirements for research scholarship. Options like holding dual appointments (at the university/college and a healthcare setting) that combined roles were identified by some as influencing their ITR. One participant described advantages of such roles:

I would like to see a new kind of faculty role or model where there is an option for joint appointments so that you don't have to have two employers expecting full-time work from you. That would allow a merging of your program of research with clinical activities.

In all focus groups, students were identified as a key factor influencing faculty ITR. Some described the enjoyment they experienced from contributing to the educational preparation of nurses as fundamental to why they remained employed in the educational institution.
I love being with my students. It is the best part of this job. Student contact, teaching them, being with them in the hospital and at the university is very rewarding.

Many faculty expressed pride in the content of their educational programs and in the calibre of graduates from their institutions. Some participants described how they positively affected population health and healthcare systems because of their role in preparing the nursing workforce. For example, one participant described:

You go home feeling like you changed the world because one nurse looked at his or her practice differently.

Increasing diversity in students, including language, background, and age was described as providing a consistent challenge for nurse faculty. Faculty identified challenges related to student interactions. Faculty across focus groups identified that more recent student cohorts frequently held a sense of entitlement that had not been held by previous student cohorts. This entitlement attitude held by many students was reported as being a disincentive to remain employed as nurse faculty. Participants in several focus groups identified stress resulting from increasingly frequent legal actions by students, regardless of academic and clinical performance. One participant stated:

Students are becoming much more litigious. Litigation involving students is becoming more of a stressor.

\subsection{External Characteristics}

Several factors external to work and work environments were identified as influencing ITR. Unionization and collective agreements were reported to impact faculty intentions (and abilities) to remain employed. Because of collective agreement stipulations some faculty, particularly part-time faculty, cited work assignments and an inability to continue employment over consecutive terms as disincentives to remain employed. They discussed how a collective agreement can impact nurse faculty ability to balance teaching requirements with other forms of scholarship which, in turn, may influence ITR. Some participants expressed aversion to being involved in strike actions experienced over recent years and expressed intentions to pursue other positions to avoid such actions in their futures. One faculty stated:

It is really disturbing to have to plan your life around the possibility of a strike. I am a sole wage earner for three other adults so it's a financial catastrophe to even contemplate being on strike.

The availability of outside opportunities was cited by some nurse faculty as affecting their ITR. In larger urban centres, alternate educational institutions were available for employment. Many participants expressed beliefs of higher wages in urban areas compared to outside urban settings. Participants in urban areas also identified that 
they had a variety of advanced practice roles to seek outside of academia. Nurse faculty living and working outside large urban centres reported being less influenced by outside opportunities as other opportunities were inferquent. One participant stated:

If we want another faculty position, we have to leave the community. There is no other university. Even within the hospital institution, there are not positions like clinician scientists and similar positions.

Participants reported that the community where they worked and lived had an impact on their ITR. Requirements for commuting to work were identified as influencing ITR. Faculty who reported having long commutes to work or long distances between worksites often felt that the time spent travelling negatively affected their work-life balance, their finances, and their desires to remain employed. For some, location of their college or university influenced their ITR. For example, one participant explained:

I like being away from large urban centres. I've had opportunity to move but have chosen to stay because I think the quality of life outside of my job is important and that is what keeps me here. Because it is a small community, we get to know everybody. I like that.

The local economy was also cited as influencing nurse faculty ITR. Cost of living in the community may have both positive and negative effect on ITR. Cost of living in urban centres was identified as being a disincentive for faculty relocating from smaller communities to larger urban areas. One faculty described why relocating may not result in financial benefit:

Our housing market is such that if I were to relocate to the same type of job in a bigger city, I would be financially disadvantaged. I would get paid the same and probably need to pay much more to live.

\section{DISCUSSION}

Previously, others have found that health status $[8,13]$, proximity to work [12] and work-life balance [14] are factors influencing nurse faculty ITR. We found that participants identified other personal characteristics such proximity to retirement (age), marital status, job opportunities for partners, and family circumstances (e.g., having dependents) as being important to their ITR. Although most personal characteristic factors are not modifiable, employers who understand their potential impact on nurse faculty ITR can focus strategies to improve certain aspects such as supporting work-life balance through flexible scheduling and provision of resources to enable nurse faculty to work from home. In addition, providing wellness programs such as stress management can promote overall health status that supports stronger nurse faculty ITR.
Our findings are mostly congruent with existing literature about the impact of work environments and organizational characteristics on nurse faculty ITR. Participants identified having a choice of employment status (full-time versus part-time) as important to ITR. Foxall et al. [13] and Gazza [14] previously identified such choices as an enticement strategy. Garbee and Killacky [12] found that having job flexibility was a source of satisfaction, but did not specifically identify full-time versus part-time status as a component of job flexibility. Allowing flexibility and mobility between part-time and full-time employment status may be an important consideration for employers as aging faculty may not want to leave employment altogether. Instead, older nurse faculty may be enticed to remain employed longer if allowed to work part-time hours and have part-time workloads.

Similar to Garbee and Killacky [12], we found that characteristics of faculty and institutional leadership were particularly important to nurse faculty ITR. Participants identified how leadership qualities of fairness, respectfulness, supportiveness, and providing constructive feedback as well as recognition were important motivators to remain in or leave employment. Many discussed the impact of organizational culture on their ITR. Participants across more than half the focus groups identified how organizational climate characteristics of competitiveness and supportiveness influenced their ITR. Further, having access to both human and material resources to support their various faculty roles was cited as important to ITR. Faculty leadership can be instrumental in establishing and sustaining work environments that support faculty ITR. However, faculty leadership may need education and support to promote their development as fair, respectful and supportive leaders.

Similar to others, we found that the quality of collegial relationships was an important influence on faculty ITR $[8,14]$. This suggests that faculty ITR can be strengthened by creating and supporting on-going opportunities for successful faculty collaboration both at work and outside work.

Modification of external characteristics that promote faculty ITR may be challenging. In our study, we found that the impact of being unionized or being part of a collective bargaining unit was reported to have considerable effect on nurse faculty ITR, particularly for nurse faculty working in Ontario colleges. Some participants reported that a collective agreement was sometimes a barrier to continued employment, especially with regards to limits placed on their contract length. This finding may be unique to the Ontario, Canada context as many Ontario colleges and universities are unionized and faculty are likely to be members of collective bargaining units. Unionization is not an influencing factor that is easily modified. However, faculty collective bargaining units and 
employer groups could agree to support increased flexibility in employment status, work hours and contract length that might strengthen nurse faculty ITR.

The content of faculty work was reported to greatly impact faculty ITR. Similar to findings of Garbee and Killacky [12], participants described the importance of autonomy in promoting their ITR. Some faculty commented that opportunities for professional autonomy were the strongest incentives to remain employed. Faculty and organizational leadership should continue to create and support opportunities to strengthen faculty autonomy. Further, variety in roles in faculty positions was frequently identified as both positively and negatively influencing ITR. Faculty leadership should routinely validate the adequacy and the burden of faculty role variety to avoid under-stimulation or work overload. In previous research, workload has been identified as having a strong influence on nurse faculty ITR $[12,13]$. Faculty also reported seeking comfort and congruence with employers' expectations of the amount and types of expected scholarship. Expectations were frequently tied to perceptions of workload adequacy. Faculty leadership should negotiate and support scholarship expectations with nurse faculty to ensure congruence and capacity for success, as well as provide resources to support scholarship expectations.

Finally, similar to previous research, interactions with students were perceived by participants as directly influencing ITR $[8,14]$. Student successes were usually identified as motivators to remain employed. The changing characteristics, expectations, and attitudes of students (e.g., attitudes of entitlement) were often seen as nonmotivators to remain employed. This suggests that there are opportunities for improving clarity between faculty and student expectations. Strategies such as forming student-faculty agreements related to course work or other faculty-student interactions (e.g., learning contracts) could be routinely implemented. Educational institutions could also develop, review, and routinely disseminate codes of behaviours for both students and faculty to enhance experiences which might strengthen nurse faculty ITR.

There are a number of limitations inherent in this study. First, to gain access to study sites, nurse faculty were invited to participate in focus groups via the Dean or Director of each faculty or school of nursing. This initial involvement of faculty or school leadership may have influenced nurse faculty decisions about participation. Confidentiality of information was reinforced to participants throughout the informed consent process. However, investigators could not guarantee that participants themselves would not discuss focus group information outside focus groups. Potential participants were informed of this before agreeing to participate. A second important potential limitation is that transferability of study findings outside Ontario, Canada colleges and universities is unknown. Factors influencing nurse faculty ITR may differ in other countries, particularly related to unionization and collective agreement conditions.

\section{CONCLUSION}

Nurse faculty ITR is influenced by at least four thematic categories of influencing factors: their own personal characteristics, work environments and organizational support, job content, and external characteristics. Modification of influencing factors is essential to strengthen nurse faculty ITR, and ultimately, nurse faculty retention. Further research is required to test and revise the hypothesized model of determinants of nurse faculty ITR to determine the strength and direction of the impact of these influencing factors. Further, the impact of influencing factors may vary in magnitude and existence across the generations of nurse faculty. Such findings could lead to generation-specific strategies to promote nurse faculty intention to remain employed.

\section{ACKNOWLEDGEMENTS}

We wish to thank Jaime Pachis and Erin Patterson for their outstanding contributions to this study. We would also like to gratefully acknowledge funding for this study received from the Ontario Ministry of Health and Long Term Care.

\section{REFERENCES}

[1] Tomblin Murphy, G., Birch, S., Alder, R., MacKenzie, A., Lethbridge, L., Little, L. and Cook, A. (2009) Tested solutions for eliminating Canada's registered nurse shortage. Canadian Nurses Association, Ottawa.

[2] Advisory Committee on Health Delivery and Human Resources (2003) A report on the nursing strategy for Canada. Health Canada, Ottawa.

http://dsp-psd.pwgsc.gc.ca/Collection/H39-554-2003E.pd $\underline{f}$

[3] Health Force Ontario (2008) Guidelines for participating in the new graduate guarantee for new graduate nurses. Nursing Secretariat, Ministry of Health and Long Term Care, Toronto. http://www.healthforceontario.ca/upload/en/work/2009 0 1_09_ngg_participation\%20guidelines.pdf

[4] Ontario Ministry of Health and Long Term Care (2011) Guidelines for application to the 2011/2012 late career nurse initiative. Nursing Secretariat, Ministry of Health and Long Term Care, Toronto.

[5] Canadian Nurses Association and Canadian Association of Schools of Nursing (2010) Nursing education in Canada statistics, 2008-2009: Registered nurse workforce, Canadian production: Potential new supply. Canadian Nurses Association and Canadian Association of Schools of Nursing, Ottawa. 
[6] Brendtro, M. and Hegge, M. (2000) Nursing faculty: One generation away from extinction? Journal of Professional Nursing, 16, 97-103. doi:10.1016/S8755-7223(00)80022-8

[7] Hessler, K. and Ritchie, H. (2006) Recruitment and retention of novice faculty. Journal of Nursing Education, 45, 150-154.

[8] Williamson, M.L., Cook, L., Salmeron, L. and Burton, D. (2010) Retaining nursing faculty beyond retirement age. Nurse Educator, 35, 152-155. doi:10.1097/NNE.0b013e3181e33982

[9] Berlin, L.E. and Sechrist, K.R. (2002) The shortage of doctoral prepared nursing faculty: A dire situation. Nursing Outlook, 50, 50-56. doi:10.1067/mno.2002.124270

[10] Yordy, K. (2006) The nursing faculty shortage: A crisis for health care. Robert Wood Johnson Foundation, Princeton. https://folio.iupui.edu/bitstream/handle/10244/533/Nursin gFacultyShortage071006.pdf

[11] Kaufman, K. (2007) More findings from the NLN/carnegie national survey: How nurse educators spend their time. Nursing Education Perspectives, 28, 296-297.

[12] Garbee, D. and Killacky, J. (2008) Factors influencing intent to stay in academia for nursing faculty in the southern United States of America. International Journal of Nursing Education Scholarship, 5, 1-15. doi:10.2202/1548-923X.1456

[13] Foxall, M., Megel, M.E., Grigsby, K. and Billings, J.S. (2009) Faculty retirement: Stemming the tide. Journal of Nursing Education, 48, 172-175. doi:10.3928/01484834-20090301-07

[14] Gazza, E.A. (2009) The experience of being a full-time nursing faculty member in a baccalaureate nursing education program. Journal of Professional Nursing, 25, 218226. doi:10.1016/j.profnurs.2009.01.006

[15] College of Nurses of Ontario (2010) Approved nursing programs. College of Nurses of Ontario, Toronto. http://www.cno.org/en/become-a-nurse/about-registration lapproved-nursing-programs/

[16] Canadian Association of Schools of Nursing (2010) Member programs. Canadian Association of Schools of Nursing, Ottawa.

http://www.casn.ca/vm/newvisual/attachments/856/Medi a/MemberPrograms-1.pdf

[17] Morgan, D.L and Krueger, RA. (1997) The focus group Kit. Sage Publications, Inc., Thousand Oaks.

[18] Mackey, M. (2007) Evaluation of qualitative research. In: Munhall, P.L., Ed., Nursing Research: A Qualitative Perspective, 4th Edition, Jones and Bartlett Publishers Inc., Mississauga, 555-566.

[19] Ayress, L. (2008) Thematic coding and analysis. In: Given, L.M., Ed., The Sage Encyclopedia of Qualitative Research Methods, Sage Publications, Los Angeles, 868-869. http://sage-ereference.com/view/research/n451.xml

[20] Morse, J., Barrett, M., Mayan, M., Olson, K. and Spiers, J. (2002) Verification strategies for establishing reliability and validity in qualitative research. International Journal of Qualitative Methods, 1, 13-21. 